
infection by simple isolates of $\mathrm{ZYMV}$ and mixed ZYMV+SQMV

\begin{abstract}
With this work, aimed to verify through artificial inoculation, the phenotypic response of plants pumpkin cv. 'Caserta' to isolates of ZYMV and ZYMV+SqMV and also check the phenotypic reaction in four genotypes of melon from an isolated mixed $(Z Y M V+S q M V)$, both coming from watermelon producing regions in the state of Tocantins. The study was conducted in a greenhouse with a screened proof aphid. The experimental design was completely randomized with five plants per plot and three replications. The inoculated plants were observed for symptoms as at 28, 33 and 38 days after first inoculation. Pumpkin plants, inoculated with simple isolate, the predominant symptoms exhibited were mosaic and parallel veins. In mixed infections there were more severe symptoms, progressing to narrowing and leaf deformation, and bubbles, parallel ridges and spur, compromising much of the leaf area of plants evaluated. In melon genotypes, the symptoms observed were more severe in Sunshine and Yellow. Genotypes in El dorado genotype was observed only mosaic and melon Valenciano was not observed symptoms.
\end{abstract}

Key-words: Curcubita sp., Cucumis melo, mixed infection symptoms.

\title{
Reação fenotípica de plantas de abóbora e melão à infecção por isolados simples de ZYMV e misto de ZYMV+SQMV
}

\section{RESUMO}

Com esse trabalho, objetivou-se verificar através da inoculação artificial, a reação fenotípica de plantas de abóbora cv. 'Caserta' a isolados de ZYMV e ZYMV+SqMV e também verificar a reação fenotípica em quatro genótipos de melão de um isolado misto (ZYMV+SqMV), ambos oriundos de regiões produtoras de melancia no Estado do Tocantins. O trabalho foi realizado em casa de vegetação com telados a prova de afídeo. O delineamento experimental utilizado foi o inteiramente casualizado com cinco plantas por parcela e três repetições. As plantas inoculadas foram observadas quanto ao aparecimento de sintomas aos 28, 33 e 38 dias após a primeira inoculação. Nas plantas de abóbora, inoculadas com o isolado simples, os sintomas predominantes exibidos foram mosaico e nervuras paralelas. Nas infecções mistas houve maior agressividade dos sintomas, evoluindo para deformações e estreitamentos foliares, além de bolhosidade, nervuras paralelas e esporão, comprometendo grande parte da área foliar das plantas avaliadas. Nos genótipos de melão, os sintomas observados foram mais agressivos nos genótipos Sunshine e Amarelo. No genótipo Eldorado observou-se apenas mosaico e no melão Valenciano não foram observados sintomas.

Palavras-chave: Curcubita sp., Cucumis melo, infecção mista, sintomatologia

\footnotetext{
*Autor para correspondência.

1 *Doutoranda em Produção Vegetal, Universidade Federal do Tocantins, Brasil, alinet4t@yahoo.com.br

${ }^{2}$ Mestranda em Produção Vegetal, Universidade Federal do Tocantins, Brasil, prinscilla_@hotmail.com

${ }^{3}$ Professor Adjunto III, Universidade Federal do Tocantins, Brasil, rwsa@uft.edu.br; rsarmento@uft.edu.br; ildon@uft.edu.br

${ }^{4}$ PesquisadorCNPh/Embrapa, Brasília, mateus.santos@embrapa.br
} 


\section{INTRODUÇÃO}

Cucurbitaceae caracteriza-se por ser uma família de plantas com relativo valor comercial, tendo destaque às abóboras (Cucurbita spp.), melancia [Citrullus lanatus (Thunb) Matsum \& Nakai] e melão (Cucumis melo L.) que, na região Norte do Brasil, apresentam alto potencial de produção devido às condições climáticas favoráveis, como temperatura elevada e altos níveis de insolação, fatores preponderantes no desenvolvimento dos frutos dessas espécies.

Segundo Vieira et al. (2005), as cucurbitáceas estão sujeitas a várias doenças causadas por vírus que podem reduzir substancialmente a sua produtividade, tanto quantitativa como qualitativamente. No caso da melancia e do melão, já foram relatadas várias espécies de vírus em plantios comerciais no Brasil, causando redução na qualidade e a quantidade dos frutos, podendo limitar o cultivo em algumas regiões (Lima et al., 2002; Oliveira et al., 2002; Lima et al., 2012).

Mais de 20 vírus podem infectar naturalmente plantas dessa família (Finetti-Sialer et al., 2012), sobressaindo-se aqueles pertencentes ao gênero Potyvirus, sendo eles: vírus da mancha anelar do mamoeiro (Papaya ringspot virus type watermelon - PRSV-W), vírus do mosaico da melancia (Watermelon mosaic virus - WMV) e vírus do mosaico amarelo da abobrinha-de-moita (Zucchini yellow mosaic virus - ZYMV), todos de importância econômica para as cucurbitáceas pela interferência nos cultivos do meloeiro, da melancia e da abóbora. A patologia dessas espécies e dos vírus, de um modo geral, pode ser observada por uma série de sintomas, que incluem mosqueado, mosaico, clorose, deformação foliar e de frutos (Oliveira et al., 2000).

Outro vírus motivo de preocupação na região Norte do país é Squash mosaic virus (SqMV), pertencente à família Comoviridae, gênero Comovirus. Uma característica preocupante desse vírus é o fato de ser transmitido por sementes, propiciando a sua introdução em áreas onde esse vírus ainda não ocorre, se tornando um meio de disseminação tanto a curta quanto a longa distância. Em estudos recentes, Alencar et al. (2012) verificaram a presença de 56\% desse vírus nas amostras analisadas. Esse vírus ocorre mundialmente causando o mosaico da abóbora em cucurbitáceas e tem sido detectado no Brasil, em áreas produtoras de estados das Regiões Norte e
Nordeste e também no Distrito Federal (Kurosawa et al., 2005).

O SqMV é, ainda, transmitido de maneira persistente por insetos da ordem Coleoptera, entre os quais destacam-se as seguintes espécies: Diabrotica speciosa, D. bivitula e Epilachma cacica. Embora o vírus não se multiplique no vetor, pode ser recuperado de fluidos de regurgitação, fezes e hemolinfa dos insetos vetores (Provvidenti e Haudenshield, 1996). A transmissão pode se dar, também, por inoculação mecânica, mas não pelo contato entre plantas (Viana et al., 2003; Kurozawa e Pavan, 1997).

Segundo Santos e Zambolim (2011), as plantas afetadas por potyvirus exibem nas folhas sintomas de mosaico, em alguns casos amarelo, acompanhado por deformações foliares e redução no desenvolvimento das plantas, podendo surgir também bolhas verde-escuras nas folhas com mosaico, dependendo do potyvirus.

Os sintomas causados pelo vírus-do-mosaico-daabóbora são variáveis e dependem da cultivar ou híbrido e da natureza do isolado. As plantas afetadas, geralmente, apresentam folhas com manchas anelares, mosaico severo e protuberâncias pequenas e alongadas sobre a superfície da folha As plantas severamente afetadas produzem frutos variegados e malformados (Viana et al., 2003).

O objetivo do trabalho foi verificar através da inoculação artificial, a reação fenotípica de plantas de abóbora cv. 'Caserta' a isolados de ZYMV e ZYMV+SqMV e também verificar a reação fenotípica em quatro genótipos de melão de um isolado misto (ZYMV+SqMV), ambos oriundos de regiões produtoras de melancia no estado do Tocantins, Brasil.

\section{MATERIAL E MÉTODOS}

Os experimentos foram realizados no Laboratório de Virologia Molecular, no Centro de Indexação de Vírus de Minas Gerais e também em casas de vegetação localizadas no Departamento de Fitopatologia (DFP) da Universidade Federal de Lavras (UFLA) e Estação Experimental da Universidade Federal do Tocantins, Campus de Gurupi, setor de Olericultura.

Foram utilizados isolados caracterizados previamente, sendo dezenove de ZYMV e dezesseis de (ZYMV+SqMV) obtidos de lavouras comerciais de produção de melancia na várzea, 
dos municípios de Formoso do Araguaia e Lagoa da Confusão.

Os isolados foram inoculados em plantas de abóbora cv. 'Caserta' e um isolado misto em quatro cultivares de melão, Sunshine ${ }^{\circledR}$ Tecnoseed; Amarelo da Syngenta; Eldorado $300^{\circledR}$ cultivar lançada em 1987 a partir de uma parceria entre a Embrapa Hortaliças e a Embrapa Semi-Árido para a incorporação de genes de resistência ao vírus WMV-1 (watermelon mosaic virus) no genoma da cultivar Valenciano Amarelo e o Valenciano (Pessoa et al., 1998).

$\mathrm{O}$ delineamento experimental utilizado foi o inteiramente casualizado, com três repetições. Cada parcela foi formada por cinco plantas de cada tratamento, totalizando quinze plantas por tratamento. $\mathrm{O}$ experimento foi conduzido em casa de vegetação, com temperatura variando de 26 a $38^{\circ} \mathrm{C}$. Em todos os casos, o plantio foi realizado em vasos de polietileno de $12 \mathrm{~cm}$ de diâmetro, com capacidade de $2 \mathrm{Kg}$, contendo uma mistura de terra, areia e esterco, na proporção 2:2:1.

Foram feitas duas inoculações artificiais, a primeira na fase cotiledonar e a segunda dois dias depois usando como inóculo tecido foliar infectado de folhas de plantas de abobrinha cv. 'Caserta', dos respectivos isolados, usando como meio solução tamponada obtida de extrato de folhas jovens, das plantas afetadas, por meio de maceração em almofariz de porcelana na presença de tampão fosfato $0,01 \mathrm{M}, \mathrm{pH} 7,0$ acrescido de sulfito de sódio na mesma molaridade, na proporção de 1:10 (peso/volume). O extrato foi friccionado nas folhas das plantas de abóbora e de melão previamente polvilhadas com abrasivo carbureto de silício (Carborundum) e, em seguida, as plantas foram lavadas com água corrente.

Foram realizadas três avaliações aos 28; 33 e 38 dias após a primeira inoculação caracterizando-se o padrão de sintoma observado.

\section{RESULTADOS E DISCUSSÃO}

Nas avaliações fenotípicas todas as plantas de abóbora cv. 'Caserta' apresentaram sintomas após a inoculação dos isolados de ZYMV ou em combinação com SqMV. Esse resultado comprova a eficiência da inoculação, pois a cv. 'Caserta' é um genótipo conhecidamente suscetível aos vírus, sendo por isso muito utilizada nos trabalhos de avaliação de virulência de isolados (Oliveira et al., 2000).

Os sintomas exibidos pelas plantas de abóbora em relação à inoculação simples com ZYMV evoluíram de mosaico leve, subdesenvolvimento das plantas, estreitamento foliar e enrolamento foliar a mosaico severo, nervuras paralelas, enação, bolhosidade, bordas franzidas e deformação foliar, sintomas característicos da presença de ZYMV Zucchini yellow mosaic virus (Tabela 1). Segundo Ramos et al. (2003) e Lopes et al. (2008) as plantas afetadas por esse vírus podem apresentar mosaico, redução do limbo foliar, deformação nas folhas e frutos, necrose e bolhas, podendo os sintomas variarem conforme o hospedeiro infectado e o isolado utilizado.

Tabela 1. Sintomas exibidos por abobrinha (Cucurbita pepo) cultivar 'Caserta' inoculadas com Zucchini yellow mosaic virus (ZYMV) em experimento de casa de vegetação. Isolados $1 \mathrm{~F}$ a $11 \mathrm{~F}$ oriundos do município de Formoso do Araguaia-TO e os demais isolados oriundos do município da Lagoa da Confusão, Estado do Tocantins.

\begin{tabular}{llll}
\hline & \multicolumn{3}{l}{ Sintomatologia de ZYMV em Abóbora cv. Caserta } \\
\cline { 2 - 4 } Isolado & 28 DAPI* & 33 DAPI & 38 DAPI \\
\hline 1-FA & $\mathrm{M}, \mathrm{Ef}, \mathrm{B} 1$ & $\mathrm{M}, \mathrm{Df}, \mathrm{Ef}, \mathrm{Bl}$ & $\mathrm{M}, \mathrm{Df}, \mathrm{Ef}, \mathrm{Bl}$ \\
2-FA & $\mathrm{M}, \mathrm{Np}$ & $\mathrm{M}, \mathrm{Np}$ & $\mathrm{M}, \mathrm{Np}, \mathrm{Et}$ \\
3-FA & $\mathrm{M}$ & $\mathrm{M}$ & $\mathrm{M}$ \\
4-FA & $\mathrm{M}$ & $\mathrm{M}$ & $\mathrm{M}$ \\
5-FA & $\mathrm{M}$ & $\mathrm{M}$ & $\mathrm{M}$ \\
6-FA & $\mathrm{M}$ & $\mathrm{M}, \mathrm{Np}$ & $\mathrm{M}, \mathrm{Np}$ \\
7-FA & $\mathrm{M}$ & $\mathrm{M}, \mathrm{Bl}$ & $\mathrm{M}, \mathrm{Bl}$ \\
8-FA & $\mathrm{M}$ & $\mathrm{M}, \mathrm{Np}, \mathrm{En}$ & $\mathrm{M}, \mathrm{Np}, \mathrm{En}$ \\
9-FA & $\mathrm{M}, \mathrm{Bl}$ & $\mathrm{M}, \mathrm{Bl}, \mathrm{Bf}, \mathrm{Ef}$ & $\mathrm{M}, \mathrm{Bl}, \mathrm{Bf}, \mathrm{Ef}$ \\
10-FA & $\mathrm{M}$ & $\mathrm{M}$ & $\mathrm{M}, \mathrm{Np}$ \\
11-FA & $\mathrm{M}$ & $\mathrm{M}$ & $\mathrm{M}$ \\
\hline
\end{tabular}




\begin{tabular}{llll} 
4-LC & M & M & M \\
11-LC & M & M, Df, Np & M, Df, Np, Sd \\
13-LC & Df, Et, Bf & Df, Et, Bf, Sd, En & Df, Et, Bf, Sd, En \\
17-LC & M & M & M \\
20-LC & M, Np & M, Np & M, Np \\
21-LC & M, Np & M, Np & M, Np \\
22-LC & M & M, B1 & M, B1 \\
23-LC & Df, Et, Bf, Ef & Df, Bf, Ef, En & Df, Et, Bf, Ef, En \\
\hline
\end{tabular}

*DAPI: dias após primeira inoculação; Bf: bordas franzidas; Bl: bolhosidade; Et: estreitamento foliar; Cs: cordão de sapato; Df: deformação foliar; Ef: enrolamento foliar; En: enação; M: mosaico; Np: nervuras paralelas; Sd: subdesenvolvimento; S/S: sem sintomas.

Nas três avaliações realizadas foram observado aumento da severidade dos sintomas no decorrer dos dias de avaliação. O isolado 8-FA (Fig. 1H) de Formoso do Araguaia causou mosaico já na primeira avaliação, avançando para enação e nervuras paralelas (Tabela 1). Por outro lado, para os isolados 3-FA, 4-FA, 5-FA, 11-FA, 4-LC e 17LC foram observados nas três avaliações somente a ocorrência de mosaico (Fig. 1C, D, E, $\mathrm{K}$, L e O; Tabela 1).

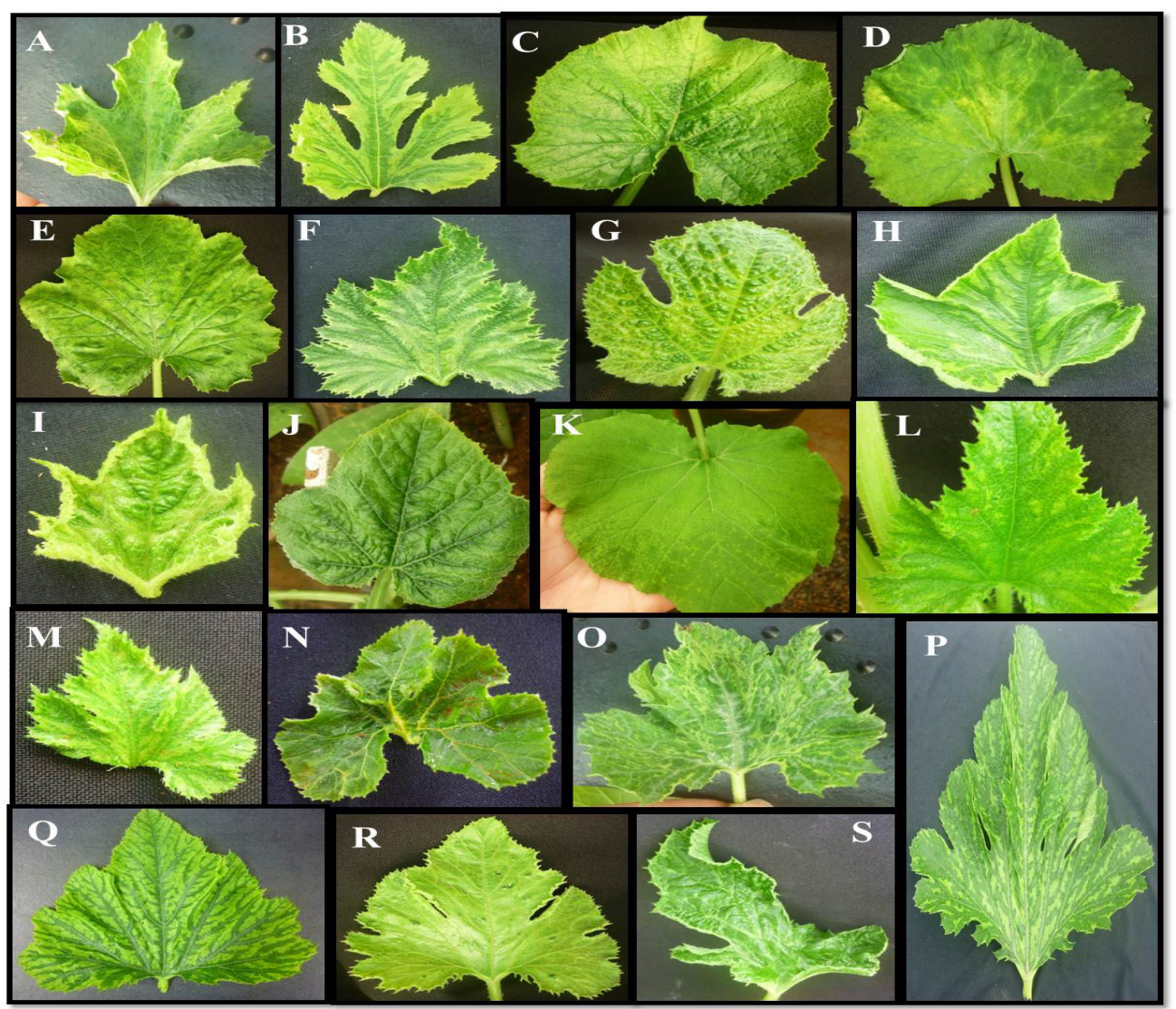

Figura 1 - Sintomas induzidos por Zucchini yellow mosaic virus (ZYMV) em plantas de abóbora cultivar 'Caserta': (B, F, H, J, M, P e Q) isolados 2-FA, 6-FA, 8-FA, 10-FA, 11-FA, 20-LC e 21-LC, respectivamente com nervuras paralelas como principal sintoma; (A, C, D, E, K, L e O) isolados 1-FA, 3-FA, 4-FA, 5-FA, 11-LC, 4-LC e 17-LC, respectivamente, com mosaico; $(\mathrm{G}, \mathrm{I}$ e $\mathrm{R})$ isolados 7FA, 9FA e 22-LC, respectivamente, com bolhosidade e (N e $\mathrm{S})$ isolados 13-LC e 23-LC, respectivamente, com deformação foliar. 
Os isolados 1-FA, 2-FA, 8-FA e 9-FA (Fig. 1A, B, $\mathrm{H}$ e I; Tabela 1), todos oriundos de Formoso do Araguaia, foram os que apresentaram três ou mais tipos de sintomas. O mosaico foi comum a todos os isolados para esse município. Já na Lagoa da Confusão, nos isolados 13-LC e 23-LC (Fig. 1N e S) não foi percebido esse sintoma, porém foram os que exibiram o maior número de sintomas ao fim da terceira avaliação, predominando deformação e estreitamento foliar, bordas franzidas, subdesenvolvimento e enação. Os isolados 2-FA, 6-FA, 8-FA, 10-FA, 11-FA, 20-LC e 21-LC exibiram nervuras paralelas como principal sintoma (Fig. 1B, F, H, J, M, P e Q; Tabela 1).

Moura et al. (2005) analisando reação de acessos de Curcubita sp. ao ZYMV verificaram que o vírus provoca forte desorganização no arranjo e na forma das células epidérmicas e do parênquima paliçádico, induzindo hiperplasia (multiplicação exagerada das células) e causando deformação foliar, sintoma verificado em algumas plantas de abóbora inoculadas com os isolados 1FA, 11LC, 13LC e 23LC (Fig. 1A, K, N e S, Tabela 1). Esse padrão de sintoma também foi verificado na infecção mista e com maior agressividade nos isolados 3-LC, 5-LC, 9-LC, 10-LC, 12-LC, 15-LC, 19-LC e 24-LC (Fig. 2B, C, G, H, I, K, N e O, Tabela 2). Os genótipos de melão 'Sunshine' e 'Amarelo' apresentaram deformação foliar (Fig. $2 \mathrm{Q}$ e R). As deformações foliares causam graves consequências para o desenvolvimento da planta, pois afetam sua fotossíntese por diminuir a área exposta, consequentemente interferindo na produtividade (Ramos et al., 2002).

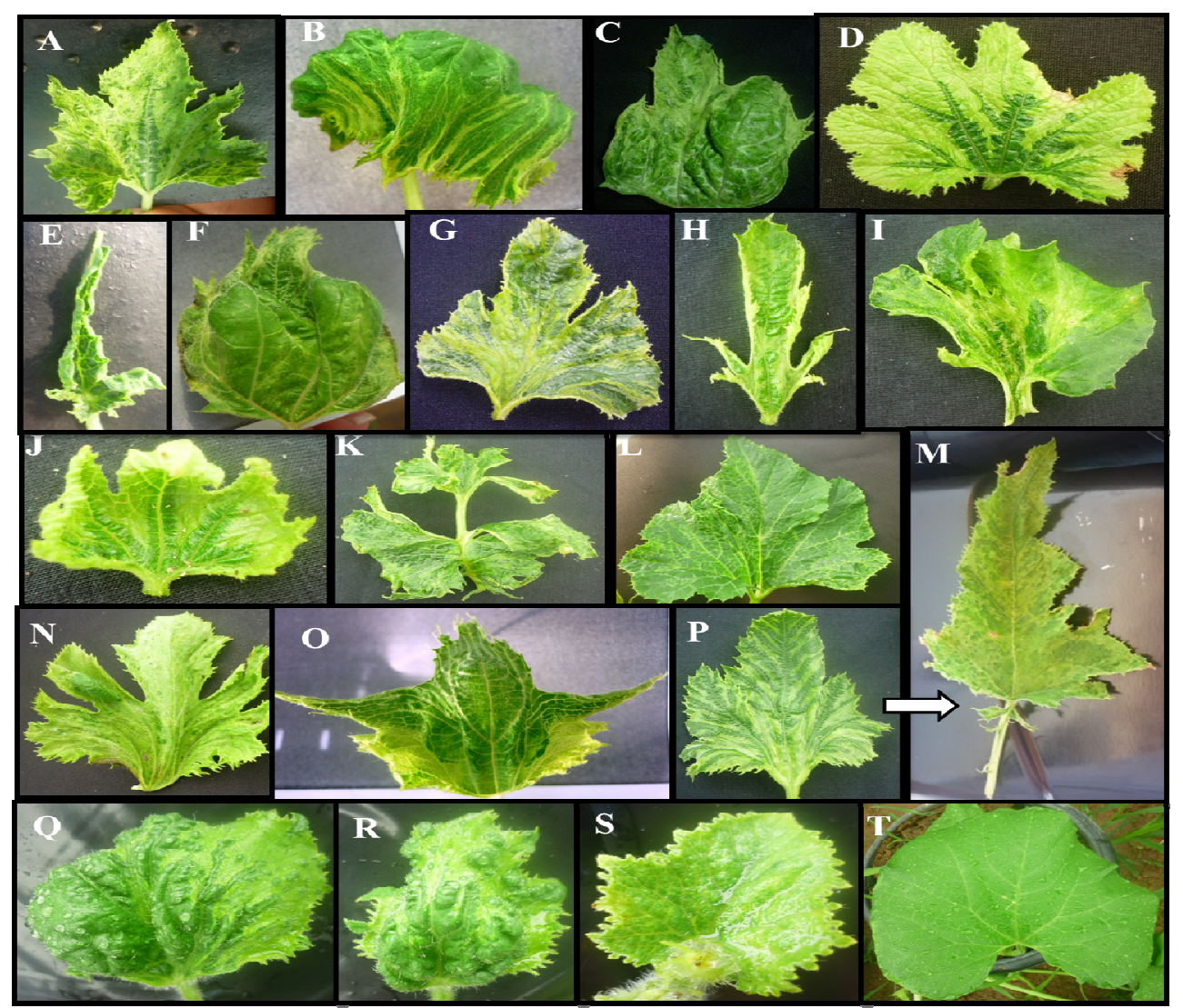

Figura 2 - Sintomas induzidos pela inoculação do isolado misto de Zucchini yellow mosaic virus (ZYMV) e Squash mosaic vírus (SqMV) em plantas de abóbora cultivar 'Caserta' : (A, B, D, G, J e P) isolados 1-LC, 3-LC, 6-LC, 9LC, 14-LC e 28-LC, respectivamente com mosaico, deformações foliares e nervuras paralelas como principais sintomas; (C, F, I, K, e O) isolados 5-LC, 8-LC, 12-LC, 15-LC, e 24-LC, respectivamente com deformação foliar e enação; (E e H) isolados 7-LC e 10-LC, respectivamente com estreitamento e enrolamento foliar; (N) isolado 19-LC com bolha como sintoma mais evidente e (M) isolado 18-LC com mosaico e crescimento do limbo foliar no pecíolo da folha (esporão). Em quatro genótipos de meloeiro (Cucumis melo): (Q) 'Sunshine' e (R) 'Amarelo' com bolhas e deformações foliares; (S) 'Eldorado' com mosaico e (T) 'Valenciano’ que não apresentou sintoma. 
Nas infecções mistas podem ocorrer relações sinérgicas, causando aumento ou decréscimo na concentração dos vírus na planta, modificação nos sintomas da doença e/ou alteração na movimentação sistêmica dos vírus (Oliveira et al., 2000). Ramos et al. (2003) ao analisarem os efeitos da interação de alguns vírus, verificaram que ao serem inoculados com ZYMV e WMV os híbridos Hy Mark, Gold Mine e Orange Flesh de meloeiro exibiram, desde o inicio da infecção, sintomas mais severos que os das plantas com infecções isoladas, evidenciando interação sinérgica entre os dois vírus em questão.

Tabela 2. Sintomas exibidos por abobrinha (Cucurbita pepo) cultivar 'Caserta' oriundos do município da Lagoa da Confusão em quatro genótipos de melão (Cucumis melo) induzidos pela combinação de (ZYMV+SqMV).

\begin{tabular}{llll}
\hline & \multicolumn{4}{l}{ Sintomatologia ZYMV+SqMV } & \\
\cline { 2 - 4 } Isolado & 28 DAPI* & 33 DAPI & 38 DAPI \\
\hline 1-LC & M, Np & M, Np & M, Np \\
3-LC & M, Np, Sd, Et, Ef & M, Np, Sd, Et, Df, Ef & M, Np, Sd, Et, Df, Ef \\
5-LC & M, Df, Et, Sd & M, Df, Et, Sd, En, Ef & M, Df, Et, Sd, En, Ef \\
6-LC & Np, Sd & Np, Sd & Np, Sd \\
7-LC & M, En, Ef & M, En, Sd, Et, Ef, & M,En,Sd, Et, Ef \\
8-LC & M, Sd, Et, En & M, Sd, Et, En & M, Sd, Et, En \\
9-LC & M, Np, Df & M, Np, Df, Sd & M, Np, Df, Sd \\
10-LC & M, Df, Et & M, Df, Et, Bf, Ef, Cs & M, Df, Et, Bf, Ef, Cs \\
12-LC & M, Df, Bl, En & M, Df, Bl, Sd, En, Ef & M, Df, Bl, Sd, Em, \\
14-LC & M, Bl, Bf, Ef & M, Bl, Bf, Ef & M, Bl, Bf, Ef \\
15-LC & M, Df, Et & M, Df, Et, Bf, Ef & M, Df, Et, Bf, Ef \\
16-LC & M, Np, Bf & M, Np, Bf, En & M, Np, Bf, En \\
18-LC & M, Et, Es & M, Et, Es & M, Et, Es \\
19-LC & M,Bl,Np,Df, Bf & M,Bl,Np,Df, Bf & M,Bl,Np,Df, Bf \\
24-LC & M, Df, Sd, Ef & M, Df, Sd, Et, Ef & M, Df, Sd, Et, Ef \\
28-LC & M, Np, Bf & M, Np, Bf & M, Np, Bf \\
\hline Melão & & & \\
\hline Sunshine & M, Bl, Df & M, Bl, Df & M, Bl, Df \\
Amarelo & M, Bl, Bf, Df & M, Bl, Bf, Df & M, Bl, Bf, Df \\
Eldorado & M & M & M \\
Valenciano & S/S & S/S & S/S
\end{tabular}

*DAPI: dias após primeira inoculação; Bf: bordas franzidas; Bl: bolhosidade; Es: esporão; Et: estreitamento foliar; Cs: cordão de sapato; Df: deformação foliar; Ef: enrolamento foliar; En: enação; M: mosaico; Np: nervuras paralelas; Sd: subdesenvolvimento; S/S: sem sintomas.

A agressividade do isolado de ZYMV constatada em infecções simples e duplas já foi relatada por Provvidenti et al. (1984) e Oliveira et al. (2000), sendo a doença ocasionada por esse vírus considerada uma das viroses mais destrutivas em cucurbitáceas, ocorrendo, tanto nos trópicos, como em regiões temperadas.

Rodrigues (2011), analisando a sintomatologia de amostras foliares de melancia de algumas cidades do estado do Tocantins verificou a presença de mosaico e bolhosidade, enquanto que em combinação com outros vírus como PRSV-W, Zucchini lethal chlorosis virus (ZLCV), Cucumber mosaic virus (CMV) e WMV os sintomas foram bem mais severos como bolhosidade, subdesenvolvimento, estreitamento foliar, deformação foliar e necrose. Os isolados 12-LC, 14-LC e 19-LC (Fig. 2I, J e L, Tabela 2) também exibiram no limbo foliar essas saliências de aparência bolhosa. $\mathrm{Na}$ infecção simples houve a presença de bolhas em dois isolados 7-FA e 22-LC (Fig. $1 \mathrm{G}$ e R, Tabela 1).

O crescimento do limbo foliar no pecíolo da folha (esporão) (Fig. 2M), sintoma típico em infecções mistas foi encontrado no isolado 18-LC do município da Lagoa da Confusão. O mesmo 
sintoma foi caracterizado no trabalho de Ramos et al. (2003) ao analisar os efeitos da interação do ZYMV com os vírus WMV e PRSV em híbridos de meloeiro, variedades de melancia e abobrinha, o que vem a aumentar o sinergismo e interação do ZYMV com outros vírus.

Quando ocorre sinergismo entre os vírus em infecção mista podem acontecer alterações nos sintomas da doença (Ramos et al., 2003). É importante salientar que hospedeiros diferentes, mesmo dentro de uma mesma espécie, podem apresentar reações sintomatológicas diferenciadas dependendo da combinação de vírus que estão causando a infecção. Dessa maneira, as estratégias para convivência com essas viroses não devem considerar os vírus isoladamente, uma vez que os dois estão ocorrendo de forma simultânea e podem causar maiores prejuízos quando afetam uma mesma planta ao mesmo tempo, como pode ser observado nesse trabalho.

Os sintomas induzidos pela infeção mista de ZYMV+SqMV em abóbora cultivar 'Caserta' se apresentaram de forma mais intensa, com um número maior de sintomas se comparado aos verificados na infeção simples. Nos isolados 1-LC, 3-LC, 6-LC, 9-LC, 14-LC e 28-LC (Fig. 2A, B, D, $\mathrm{G}$, J e P, Tabela 2) respectivamente exibiram mosaico, deformações foliares e nervuras paralelas como principais sintomas. Foi verificado nos isolados 5-LC, 8-LC, 12-LC, 15-LC, e 24-LC (Fig. 2C, F, I, K, e O, Tabela 2) deformação foliar e enação. Verificou-se também estreitamento e enrolamento foliar nos isolados 7-LC e 10-LC (Fig. 2E e H). Embora as plantas não sejam destruídas pelos vírus, os cultivos infectados têm o processo de produção severamente interrompido, produzindo frutos anormais e/ou deixando de produzir (Clough, 1995).

No melão Amarelo foram observados os sintomas mais severos. O genótipo 'Eldorado' (Fig. 2S) exibiu apenas mosaico, já o melão 'Valenciano' apresentou-se assintomático, sendo possivelmente tolerante aos vírus inoculados. $\mathrm{Na}$ década de 80 esse genótipo foi alvo de estudos para a incorporação de genes de resistência a vírus, método que poderia ter uma abrangência maior já que vem dando resultados (Lopes 1997).

Como os isolados de ZYMV e SqMV foram coletados de lavouras comerciais de melancia da região sul do estado do Tocantins, é de suma importância a preocupação dos produtores com a qualidade fitossanitária das sementes que estão utilizando nas suas lavouras, evitando sementes de frutos produzidos na região, pois essas possuem um maior risco de estarem contaminadas com vírus, já que o SqMV é transmitido via semente e os sintomas ocasionados pela combinação dos dois vírus foram bastante agressivos, por isso a importância de se tomar medidas preventivas antes de iniciar um plantio e uma decisão simples e correta como se plantar apenas sementes certificadas pode garantir uma lavoura livre de sintomas tão prejudiciais à cultura.

\section{CONCLUSÕES}

Os sintomas mais comuns observados pela infecção por ZYMV foram mosaico e nervuras paralelas.

A sintomatologia das plantas de abóbora em relação à inoculação mista pelos vírus ZYMV e SqMV foi mais severa durante o período avaliado, evoluindo para deformações e estreitamentos foliares, além de bolhosidade, nervuras paralelas e esporão, comprometendo grande parte da área foliar.

Nos genótipos de melão, somente o Melão Valenciano não apresentou sintomas característicos de vírus.

\section{REFERÊNCIAS}

ALENCAR, N. E.; FIGUEIRA, A. R.; ALMEIDA, J. E. M.; LUCAS, M. A.; SANTOS, L. B.; NASCIMENTO, I. R. Identificação biológica e molecular de vírus detectados em espécies de cucurbitáceas provenientes do estado do Tocantins. Journal of Biotechnology and Biodiversity, v. 3, p. 32-37, 2012.

CLOUGH, G. H. Coat protein transgenic resistance to watermelon mosaic and zucchini yelow mosaic virus in squash and cantaloupe. Plant Disease, v. 79, p. 1107-1109, 1995.

FINETTI-SIALER, M. M; MASCIA, T.; CILLO, F.; VOVLAS, C.; GALLITELLI, D. Biological and molecular characterization of a recombinant isolate of Watermelon mosaic virus associated with a watermelon necrotic disease in Italy. European Journal Plant Pathology, v. 132, p. 317-322, 2012.

KUROZAWA, C. e PAVAN, M. A. Doenças das cucurbitáceas. In: KIMATI, H.; AMORIM, L.; BERGAMIN FILHO, A.; CAMARGO, L. E. A.; 
REZENDE, J. A. M. (Ed.) Manual de Fitopatologia. São Paulo: Agronômica Ceres, v. 2, p. 325-337, 1997.

KUROSAWA, C.; PAVAN, M. A.; REZENDE, J. A. M. Doenças das cucurbitáceas. In: KIMATI, H.; AMORIM, L.; REZENDE, J. A. M.; BERGAMIN FILHO, A.; CAMARGO, L. E. A. Manual de Fitopatologia - Doenças das plantas cultivadas, 4. ed., São Paulo, Agronômica Ceres, v. 2, p. 293-310, 2005.

LIMA, J. A. A.; NASCIMENTO, A. K. Q; RADAELLI P; PURCIFULL DE. Serology Applied to Plant Virology. In: Moslih Al-Moslih. (Org.). Serological Diagnosis of Certain Human, Animal and Plant Diseases, v.1. p.71-94, 2012.

LIMA, J. A. A.; QUEIROZ, M. A.; RAMOS, N. F.; GONÇALVES, M. F. B. Sintomas atípicos em frutos de meloeiro e de melancia ocasionados por Watermelon mosaic virus. Fitopatologia Brasileira, v. 27, n.4, p. 546-551, 2002.

LOPES, J. F.; CARVALHO, S. I. C.; PESSOA, H. B. S. V. Recursos Genéticos de melão e pepino na Embrapa Hortaliças. Recursos Genéticos e Melhoramento de Plantas para o Nordeste Brasileiro, 8p, 1997,

LOPES, C. A.; REIS, A.; LIMA, M. F. Principais Doenças da Cultura da Melancia no Brasil. Circular Técnica n. 61, julho de 2008.

MOURA, M. C. C. L.; ZERBINI, F. M.; SILVA, D. J. H.; QUEIROZ, M. A. Reação de acessos de Cucurbita sp. ao Zucchini yellow mosaic virus (ZYMV). Horticultura Brasileira, v.23, n.2, p.206-210, 2005.

OLIVEIRA, V. B.; LIMA, J. A. A.; VALE, C. C.; PAIVA, W. O. Caracterização biológica e sorológica de isolados de potyvirus obtidos de cucurbitáceas no Nordeste Brasileiro. Fitopatologia Brasileira, v. 25, p. 628-636, 2000.

OLIVEIRA, V. B.; QUEIROZ, M. A.; LIMA, J. A. A. Fontes de resistência em melancia aos principais potyvirus isolados de cucurbitáceas no nordeste Brasileiro. Horticultura Brasileira, v. 20, p. 589-592, 2002.
PESSOA, H. B. S. V.; AVILA, A. C.; DELLA, VECCHIA, P. T.; ARAÚJO, J. P.; OLIVEIRA, L. O. B. Eldorado 300: melão resistente ao vírus do mosaico de melancia WMV - 1. Horticultura Brasileira, v. 6, n. 1, p. 40-41, 1998.

PROVVIDENTI, R., GONSALVES, D.; HUMAYDAN, H. J. Occurrence of Zucchini yellow mosaic virus in cucurbits from Connecticut, New York, Flórida, and California. Plant Disease, v. 68, p.443-446, 1984.

PROVVIDENTI, R.; HAUDENSHIELD, J. S. Squash Mosaic. In: ZITTER, T. A.; HOPKINS, D. L.; THOMAS, C. E. (Ed.) Compendium of cucurbit diseases. Minnesota: The American Phytopathological Society, p. 87, 1996.

RAMOS, N.F. Estudo da interação entre vírus e do comportamento de genótipos de meloeiro e melancia. 100 f. Dissertação (Mestrado em Fitopatologia) - Curso de Pós-Graduação em Fitopatologia, Universidade Federal do Ceará, Fortaleza, 2002.

RAMOS, N. F., LIMA, J. A. A. \& GONÇALVES, M. F. B. Efeitos da interação de potyvirus em híbridos de meloeiro, variedades de melancia e abobrinha. Fitopatologia Brasileira, v. 28, p. 199203. 2003.

RODRIGUES, A. M. Ocorrência, distribuição e diagnose de viroses associadas à cultura da melancia no estado do Tocantins. 97f. Dissertação de mestrado. Universidade Federal do Tocantins, Gurupi, 2011.

SANTOS, G. R. e ZAMBOLIM, L. Tecnologias para produção sustentável da melancia no Brasil. Universidade Federal do Tocantins, 2011.

VIANA, F. M. P.; NOGUEIRA, E. M. C.; FERRARI, J. T.; SANTOS, A. A. Doenças do meloeiro. In: FREIRE, F. das C.O.; CARDOSO, J. E.; VIANA, F. M. P. (Ed.). Doenças de fruteiras tropicais de interesse agroindustrial. Brasília, DF: Embrapa Informação Tecnológica; Fortaleza: Embrapa Agroindústria Tropical, p. 107-143, 2003.

VIEIRA, J. V.; AVILA, A. C.; PINTO, M. N.; SILVA, B. M. da; BORGES, C. L. Avaliação da 
coleção de germoplasma de melancia da Embrapa Hortaliças para tolerância a viroses. Brasília: Embrapa Hortaliças (Boletim de Pesquisa e Desenvolvimento). 2005. 